EPISTEME KOINONIA

Revista Electrónica de Ciencias de la Educación, Humanidades, Artes y Bellas Artes

Año III. Vol III. N ${ }^{\circ}$. Enero - Junio, 2020

Hecho el depósito de Ley: FA2018000022

ISSN: 2665-0282

FUNDACIÓN KOINONIA (F.K).

Santa Ana de Coro, Venezuela

Lisbeth Borregales

http://dx.doi.org/10.35381/e.k.v3i5.529

\title{
Génesis y evolución socio-histórica de la macro categoría cultura escrita
}

\section{Genesis and socio-historical evolution of the written culture macro category}

\author{
Lisbeth Borregales \\ lisbethborregales@hotmail.com \\ Universidad Nacional Experimental Francisco de Miranda, Monseñor Iturriza \\ Venezuela \\ https://orcid.org/0000-0003-2281-5772
}

Recepción: 01 Agosto 2019

Revisado: 15 Agosto 2019

Aprobación: 15 Septiembre 2019

Publicación: 01 Enero 2020

\begin{abstract}
RESUMEN
En este artículo se presenta un bosquejo socio-histórico de la génesis y evolución de la cultura escrita de la cual han emergido las propuestas pedagógicas para enseñar y aprender a escribir a lo largo del tiempo. Se trata de una investigación documental analítica, mediante el cual se aborda desde de una visión holística, transdisciplinaria, cómo han evolucionado las teorías sobre la cultura escrita y la pedagogía sobre la escritura. Con el propósito de sistematizar la información sobre este tópico, de conocer la evolución de las teorías sobre los modelos de escritura y su impacto en la práctica docente. Por consiguiente se expone una descripción de los sistemas de escritura en sus contextos socio-históricos, sus usos, prácticas pedagógicas a fin de contribuir a una reflexión/acción que nos lleve al cambio del modelo tradicional de la enseñanzaaprendizaje de la lengua escrita por un modelo centrado en la pedagogía discursiva de la escritura.
\end{abstract}

Palabras clave: Lengua escrita; sistema de escritura; investigación pedagógica; investigación sobre la lectura (Palabras tomadas del Tesauro UNESCO).

\section{ABSTRACT}

This article presents a genesis and evolution socio-historical outline of the written culture from which pedagogical proposals to teach and learn to write have emerged over time. It is a documentary - analytical investigation, by which it is approached how theories based on written culture and pedagogy about writing have evolved from a holistic and transdisciplinary vision, with a view to systematize information on this topic to know the 


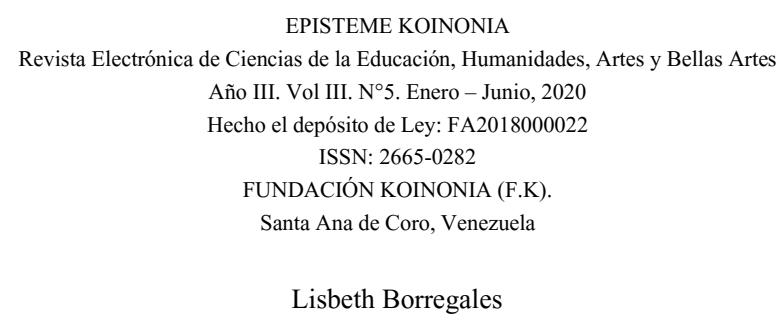

evolution of theories regarding writing models and their impact on teaching practice. Therefore, a description of the writing systems in their socio-historical contexts, their uses and pedagogical practices are exposed in order to contribute to a reflection / action that leads us to the change of the traditional teaching-learning model of the written language by a model focused on the discursive pedagogy of writing.

Keywords: Written language; writing systems; educational research; reading research. (Words taken from UNESCO Thesaurus).

\section{INTRODUCCIÓN}

En primer lugar emerge la necesidad de establecer ¿qué implica la cultura escrita en el marco general de las teorías que abordan la lengua escrita? Pero antes conviene aclarar que este ensayo se inscribe dentro de una investigación en relación a la evaluación de la competencia escrita a partir de registros descriptivos de las producciones escritas de estudiantes de Educación Media del Estado Falcón, Venezuela (2018-2019).

Por consiguiente, el propósito de este empeño es documentar el modo, las prácticas y los usos que ha tenido la lengua escrita dentro de esa competencia que es la cultura escrita. ¿Para qué? Este abordaje contribuirá a la identificación y construcción de las redes semánticas conceptuales para el establecimiento de las relaciones entre categorías y subcategorías. Asimismo para la definición y clasificación de las mismas en: dimensiones, atributos, variables y patrones. Pues estas categorías irán orientado el proceso para la selección de la categoría central, para su saturación y finalmente su teorización. En resumen, este procedimiento aportará datos teóricos que serán válidos para la confrontación de los datos que se obtengan del fenómeno objeto de estudio a través de la triangulación teórica cuyo procedimiento corresponde al Paradigma Cualitativo bajo la modalidad de la Teoría Fundamentada.

Desde esta perspectiva, es pertinente hacer un ejercicio de comprensión hermenéutica en torno a los planteamientos teóricos de un grupo de investigadores sobre el papel de la cultura escrita y su vinculación con los procesos cognitivos, lingüísticos, pragmáticos 


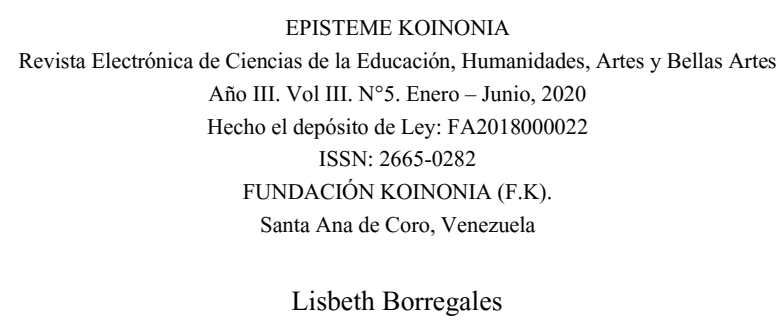

y discursivos del ser humano. Cuyos procesos deben estar inmersos en la enseñanza de la lengua escrita.

Al respecto Olson, (1998; p.301) explicó que: "La cultura escrita, es desde luego, la competencia con la escritura; diferentes escrituras establecen diferentes competencias. La cultura escrita está orientada funcionalmente [...] a convertirse en letrado en determinado campo es aprender a compartir un paradigma." $\mathrm{Y}$ eso ¿qué significa? Implica que al escribir participamos en una comunidad textual que comparte un conjunto de textos, de interpretaciones y de creencias tal como lo planteó Kuhn, (1995). En consecuencia cada época ha creado una cultura escrita de acuerdo a los factores socio-históricos de esa sociedad, a la evolución de su pensamiento y al desarrollo tecnológico. De ahí la necesidad de su apropiamiento por la sociedad letrada, académica y profesional.

Desde este enfoque, la macro-categoría cultura escrita es una conceptualización que ha sido empleada en otros estudios por investigadores internacionales y nacionales de la talla de Jack Goody, (1963,1968, 1987, 1996); R. Harris (1986); David Olson $(1977,1980,1990,1994,1998) ;$ E. Havelock (1963,1976,1982,1991); Walter Ong (1976,1982); Roger Chartier (1999); Josefina Peña (2008); Glenys Pérez (2008); Pilar Figueroa, (2011); Rudy Mostacero $(2017,2012)$ y Stella, Serrano (2003), entre otros.

En este sentido y para efecto de este artículo se empleará la noción de cultura escrita (literacy) que ha emergido de los trabajos del psicólogo cognitivo Olson, (1998) quien la define:

[...] Es la competencia para explotar un conjunto determinado de recursos culturales. Es la evolución de esos recursos, en conjunción con el conocimiento y la habilidad para explotarlos con fines determinados. La cultura escrita en occidente no es solo aprender el abecedario, es aprender a usar los recursos de la escritura para un conjunto culturalmente definido de tareas y procedimientos. (Pp.64-65)

Por lo tanto, este análisis nos permitirá construir una visión holística, integral y transdisciplinaria a través de una reflexión socio-histórica de la cultura escrita desde sus 


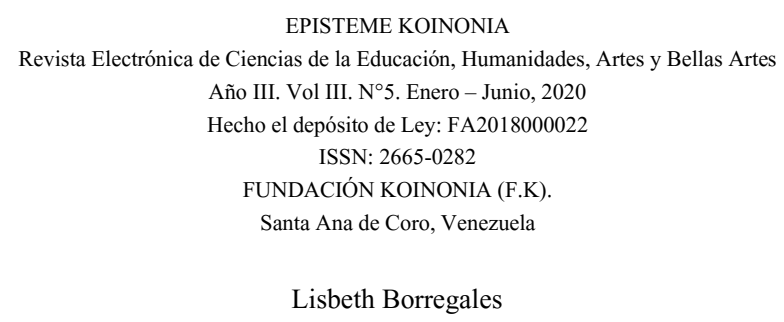

orígenes hasta su evolución actual y cómo esta ha incidido en los modelos pedagógicos de la escritura con la finalidad de revisar su alcance. Al respecto se establece que estos ensayos se estructurarán por periodos. En virtud de las limitaciones de espacio dentro de este formato. Esto implicará un continuo en la temática de una serie de ensayos con los cuales se organiza el presente trabajo.

En segundo lugar, esta retrospección comprenderá diversas épocas socio-históricas, que abarcan desde la Prehistoria con la invención de la escritura. Seguidamente se abordará los periodos que comprenden la historia desde la Antigüedad o también Ilamada Edad Clásica. Luego se revisará la Edad Media. Después la Edad Moderna hasta llegar a la Edad Contemporánea. Cabe señalar que en cada época se examinará las concepciones predominantes sobre la lengua escrita, los usos que de ella se generan en la práctica pedagógica y el tipo de competencia que de ella se deriva de su aprendizaje.

Para tal fin se hará un abordaje documental, comparativo empleando categorías epistemológicas de la psicolingüística, de la sociolingüística, de la pragmática, de la semántica ydel análisis del discurso. En síntesis, se usará una metodología para construir categorías desde la perspectiva de la Teoría Fundamentada. Para ese propósito se usará el enfoque de una lingüística interdisciplinaria con las cuales se analizará las distintas civilizaciones que a lo largo del tránsito socio-histórico fueron aportando sus saberes, sus prácticas y sus procedimientos y dieron origen a la escritura mediante la creación del alfabeto. Y como esta "tecnología comunicacional" tal como la denomino McLuhan, (1962) generó una práctica de lectura y de escritura para un grupo social muy restringido. Inclusive dentro de la misma nobleza. Pero luego otros acontecimientos socio-históricos donde han participado otros actores claves promovieron su democratización.

En síntesis, la humanidad entera ha pasado históricamente por un largo proceso de adquisición, desarrollo y consolidación de los sistemas de escritura al igual que cada ser humano. En este sentido afirmó Peña, (2008, p.98): "La cultura escrita es un 
EPISTEME KOINONIA

Revista Electrónica de Ciencias de la Educación, Humanidades, Artes y Bellas Artes

Año III. Vol III. N ${ }^{\circ}$. Enero - Junio, 2020

Hecho el depósito de Ley: FA2018000022

ISSN: 2665-0282

FUNDACIÓN KOINONIA (F.K)

Santa Ana de Coro, Venezuela

Lisbeth Borregales

producto social, cuya génesis se remonta a épocas antiquísimas y es el resultado de una larga construcción histórica que comienza con caracteres de dibujos, incididos con un punzón en tablillas de barro". Veamos en este apartado ese proceso desde su invención hasta la formación de la cultura escrita en los pueblos de la antigüedad.

\section{La Invención de la Escritura en la Era Prehistórica. Transición entre el Homínido y el Homo sapiens}

El hombre del paleolítico para adaptarse y dominar al mundo desarrolló un conjunto de capacidades y técnicas conformando una data o un registro, que se fue legando a las sucesivas generaciones mediante la imitación. Este conocimiento contribuyó a la revolución que efectuó posteriormente el hombre del neolítico al desarrollar la técnica para la agricultura.

Por consiguiente, el hombre del paleolítico aprovechó todo a su máxima expresión, convencido como estaba que la idea de grupo era imperante y la propiedad era colectiva y matriarcal. Lo importante entonces era conservar la vida. De ahí que, fabricó productos y utensilios para la caza, la pesca, la recolección de alimentos y también desarrolló otra facultad el arte rupestre dando así indicios de los procesos cognitivos que se venían gestando en sus mentes relacionadas con la simbolización o representación. En este mismo sentido, Strauss, (1966) aportó una descripción que nos mostró la implicancia de esos hechos:

Transformar una hierba en una planta cultivada, una bestia salvaje en un animal doméstico, producir en ambos casos, propiedades nutricias 0 tecnológicas útiles que estaban originalmente ausentes [...] Transformar raíces o semillas tóxicas en alimentos o usar su veneno para la caza, la guerra o los rituales. No hay duda de que todos estos logros requirieron una actitud genuinamente científica, un interés atento y sostenido y un deseo de conocimiento por el conocimiento mismo [...] el hombre neolítico, o histórico temprano, fue, pues, el heredero de una larga tradición científica. (Citado por Olson, 1998; p.44). 
EPISTEME KOINONIA

Revista Electrónica de Ciencias de la Educación, Humanidades, Artes y Bellas Artes

Año III. Vol III. N ${ }^{\circ}$. Enero - Junio, 2020

Hecho el depósito de Ley: FA2018000022

ISSN: 2665-0282

FUNDACIÓN KOINONIA (F.K)

Santa Ana de Coro, Venezuela

Lisbeth Borregales

De ahí que el hombre neolítico, quien había logrado la adquisición del conocimiento sobre la agricultura comenzó a tener sentido de permanencia sobre su espacio. Entonces afinó su organización social, puesto que las hordas pasaron hacer clanes, por lo que se requirió que se establecieran los criterios para la selección de los jefes de clanes de acuerdo al tipo de conocimiento o fuerza física que poseyera. Al respecto Ponce, (1981) señaló:

En los primeros tiempos de la comunidad primitiva cualquiera podía ser, momentáneamente juez o jefe; ahora la estructura social empezaba a complicarse se requerían para determinadas funciones ciertos conocimientos que los poseedores empezaron a apreciar como fuente de dominio [...] cada organizador educaba a sus parientes para el desempeño de su cargo [...] y en esa forma, las funciones directrices se volvieron patrimonio de un grupo reducido que defendía celosamente sus secretos. (p.37)

Paralelamente a esta realidad se crearon los instrumentos para la domesticación de los animales. A juicio del autor mencionado los cambios se produjeron al modificar las técnicas de producción, que trajo un mayor rendimiento en la producción, pues ya se había dado la división del trabajo. De esta manera Ponce señala que:

Las modificaciones introducidas en la técnica especialmente, la domesticación de los animales y su aplicación en la agricultura como auxiliares del hombre, acrecentaron de tal modo las fuerzas del trabajo humano que la comunidad empezó a crear desde entonces más de lo necesario para su propio sustento [...] Cada uno de los productores, aligerando un poco de trabajo, se dio a producir no sólo para sí, sino también para cambiar con las tribus vecinas. (p.34)

Hubo por tanto, la división del trabajo en agricultores y pastores como un hecho trascendental de la prehistoria. Con el transcurrir del tiempo la dirección del trabajo se separa del trabajo mismo; las fuerzas mentales de las fuerzas físicas. Por lo que se estratifican a los grupos sociales de acuerdo a su conocimiento y bienes. Surgiendo dentro de los estamentos el dominado y el dominador. Dentro de ese proceso se genera un desprecio hacia el trabajo manual ejecutado por el dominado. Toda esa situación conlleva a la sustitución de la sociedad matriarcal por una sociedad patriarcal. 
EPISTEME KOINONIA

Revista Electrónica de Ciencias de la Educación, Humanidades, Artes y Bellas Artes

Año III. Vol III. N ${ }^{\circ}$. Enero - Junio, 2020

Hecho el depósito de Ley: FA2018000022

ISSN: 2665-0282

FUNDACIÓN KOINONIA (F.K)

Santa Ana de Coro, Venezuela

Lisbeth Borregales

Entonces esa sociedad tribal patriarcal elaboró un aparato mítico-religioso apareciendo así estructurado el elemento simbólico a nivel cognitivo, por lo que "los magos, los sacerdotes, y los sabios depositarios, primero; dueños, después del saber de la tribu asumen poco a poco, junto a la función general de consejeros, la otra más restringida de iniciadores. Por consiguiente estos estamentos sociales ostentan un poder, "cada tribu ha ido recogiendo a través de los años una larga experiencia que fue cristalizando en tradiciones y mitos" (Ponce, 1981; p.38). Esta educación se trasmitía mediante la oralidad y la imitación que se efectuaba por medio de ciertas pruebas que implicaban los ritos de los iniciados, de los escogidos. Al respecto Olson, (1998) sostiene:

Podemos equivocarnos si buscamos en la cultura escrita una explicación de la evolución del pensamiento neolítico, aunque hay algunas pruebas de que una preescritura, bajo la forma de fichas puede datar del paleolítico, así como los impresionantes dibujos de las cuevas de Altamira y Lascaux. (p. 44)

En conclusión, este periodo denominado prehistoria "es la primera etapa de la historia del hombre, la cual tiene su principio en la aparición del primer hombre hasta la invención de la escritura" León y Pinzón, (1997, p.1). Al respecto las investigaciones reportan que cuando se origina la invención de la escritura se produce una nueva etapa. Veamos en qué condiciones se produjo ese sistema de escritura:

Una forma gráfica extremadamente importante desde la cual puede haberse desarrollado todos los sistemas de escrituras en Occidente es el sistema de fichas desarrollado en Mesopotamia con fines contables [...] el sistema, inventado por los antiguos sumerios, aproximadamente en la época en que las sociedades de cazadores y recolectores estaban dando paso a un modo de vida agrícola, consistía en conjunto de fichas de arcillas con formas distintivas, usadas para registrar ovejas, vacas y otros animales así como mercaderías [...] se comenzó a perforar las fichas, de tal modo que podían insertarse juntas" (Olson, 1998; p. 96).

Del planteamiento de Olson se infiere que la escritura nace como tal, cuando dejo de ser emblema y paso ser un sistema combinación de emblemas generativo, cuando han adquirido una sintaxis como la lengua "es la sintaxis lo que hace que un sistema 


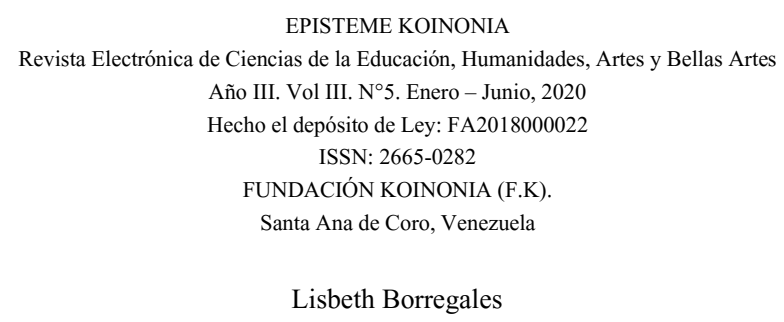

gráfico "generativo" permita la combinación y recombinación de los símbolos para expresar un amplio espectro de significados" (Ob.cit; p.97). Por consiguiente, del análisis se deduce que cuando los signos lingüísticos adquirieron una sintaxis fueron sistemas de escrituras. Al respecto, la invención de la escritura proveyó un modelo para la lengua y para el habla y de esta manera el ser humano se pudo comunicar y establecer acuerdos para desarrollar sus actividades económicas:

Las invenciones de los escribas imponían un tipo de lectura que hacía posible que se considerara a la lengua como compuesta por palabras relacionadas por medio de una sintaxis. La escritura proporcionaba, pues, el modelo para la producción del habla (en la lectura) y para la introspección consciente del habla en tanto compuesto de constituyentes gramaticales, es decir, palabras." (Ob.cit; Pp.99-101)

Otra versión acerca de la invención de la escritura la proporcionaron los trabajos de Havelock (1982) y Gelb (1963). Para estos investigadores la escritura fue inventada a partir del silabario de una lengua semita, posiblemente el fenicio, que vivían en el norte de la Medialuna Fértil, zona cultivable que conectaba las civilizaciones de babilonia y la egipcia. (Citados por Olson, 1998; p.107).

Para finalizar con el origen de la escritura es importante resaltar que hubo una transición entre la escritura consonántica y la escritura alfabética. Esta se produjo cuando la escritura semítica se adaptó a una lengua no semítica como era el griego y se produce entonces el alfabeto. Pasemos ahora a examinar a los pueblos de la antigüedad en el siguiente apartado.

\section{La Cultura Escrita en los Pueblos de la Antigüedad}

En ese periodo socio-histórico que comprende la Antigüedad o también llamada Edad Clásica tuvieron sus asentamientos los pueblos agrícolas entre los cuales sobresale la civilización egipcia, cuyo espacio geográfico está ubicado al norte-este de África, enclavada en los márgenes del río Nilo. Los egipcios fueron el resultado de un proceso de mestizaje con los pueblos, que estaban a su alrededor como eran: los semitas, los 
EPISTEME KOINONIA

Revista Electrónica de Ciencias de la Educación, Humanidades, Artes y Bellas Artes

Año III. Vol III. N ${ }^{\circ}$. Enero - Junio, 2020

Hecho el depósito de Ley: FA2018000022

ISSN: 2665-0282

FUNDACIÓN KOINONIA (F.K)

Santa Ana de Coro, Venezuela

Lisbeth Borregales

libios y los nubios. En relación a la cultura escrita, los egipcios desarrollaron capacidades intelectuales, entre ellas la escritura como medio de comunicación mediante los jeroglifos. Hay que decir también, que en este tipo de escritura las palabras se representan con símbolos o figuras. Por lo tanto estas:

Constituyen una estructura compleja, de vocabulario muy rico y de gramática complicada. Algunos de estos jeroglifos son ideogramas. Otros jeroglifos y los fonogramas representan de una a tres consonantes. Para las operaciones corrientes, los escribas utilizaban una escritura simplificada la hierática y la demótica para asuntos más relevantes. (Larousse, 2007; p.28).

En consecuencia, sus obras literarias constituyeron una evidencia del uso de la lengua escrita entre las que destacan: las Lamentaciones de Isis y Neftis, la Letanías del Sol, el Libro de los Caminos, el Libros de los Muertos y la Sátira de los Oficios. Esta última habla de la dureza de la vida de los artesanos egipcios y del despreció, que los letrados sentían por ellos. Además muestra el papel relevante que ocupaba el escriba en la vida social egipcia, puesto que el escriba simbolizaba al hombre, que había alcanzado la posición más alta.

Cabe mencionar que los escribas también cumplían la función de cobradores de impuesto. Entre ellos había escribas jueces o príncipes de los países recién conquistados. Estos sólo pensaban enriquecerse en el menor tiempo posible. Al respecto Goody, (1968,p.48) señala "en Egipto y en Mesopotamia como en China, surgió una élite letrada de expertos religiosos, administrativos y comerciantes, que conformó una burocracia gobernante centralizada." Esos grupos ostentaban un poder dentro de ese contexto socio-histórico, además la lengua escrita tenía un sentido funcional, pues se usaba para el ejercicio de ese poder. En ese sentido, su competencia o dominio implicaba un privilegio que distinguía al escriba como persona calificada. Ahora bien ¿cómo era el modelo de enseñanza que recibían estos grupos privilegiados? Al respecto:

[...] la escuela se consideraba como el recinto en el que se dedicaba el tiempo para desarrollar en sus asistentes, ciertas habilidades básicas en lectura, escritura y cálculo. En Mesopotamia y Egipto el aprendizaje de la 


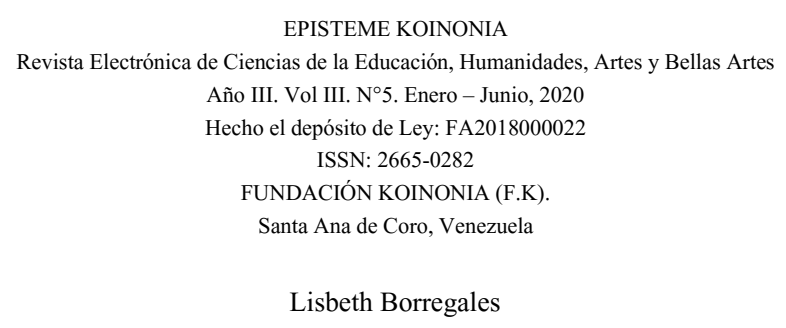

escritura era de bastante complejidad, por tanto requería años de estudio y los escribas gozaban de un alto prestigio social. La escritura era practicada por personas muy calificadas los escribas profesionales, instruidas especialmente para ello. Se les recompensaba con una elevada posición en la sociedad y con privilegios específicos, como la exención de impuestos. (Peña, 2008; Pp.35-98).

A partir dato se infiere que el modelo de enseñanza se basaba en la repetición y adquisición del código escrito para uso burocrático. En este marco de ideas es relevante señalar "que la escritura alentó el crecimiento de la actividad mágicoreligiosa. El sacerdote era el hombre educado, el letrado, el intelectual, que controlaba la comunicación natural como la sobrenatural. En otras palabras, era el privilegiado por la capacidad de manejar la escritura (Goody, 1968, p.26).

Con respecto a la civilización Mesopotámica enclavada entre río Éufrates y Tigris, región montañosa de Armenia que se extiende hasta el norte de la región pantanosa en las que esos ríos vierten sus aguas en el Golfo Pérsico. En ese árido escenario, donde se desarrolló la agricultura, el comercio, la medicina, la astronomía, la literatura y la música, cuyos saberes tuvieron su base en el dominio de los sistemas de escritura.

Cabe destacar que dentro de ese territorio tuvieron sus asentamientos los pueblos caldeos, sumerios y asirios que se formaron producto del mestizaje. En el caso de los caldeos legaron como aporte a la cultura escrita el Código Hammurabi, el cual fue creado por el VI rey del mismo nombre, quien dictaba las leyes que regían a la nobleza, a los campesinos, artesanos libres y a los esclavos. De esta forma se evidenció que la lengua escrita también era empleada no sólo para uso contable sino que la misma servía para controlar a los ciudadanos, es decir la escritura se empleaba para imponer reglas y castigos de ahí su uso funcional.

Al respecto es oportuno mencionar que el rey Hammurabi tenía su sede principal de gobierno en Babilonia convirtiéndose esta en un gran centro de esplendor en las artes arquitectónicas, con sus esplendidos jardines colgantes, pues durante su reinado se desarrolló la ingeniería hidráulica. En cuanto a la lengua escrita los pueblos de 


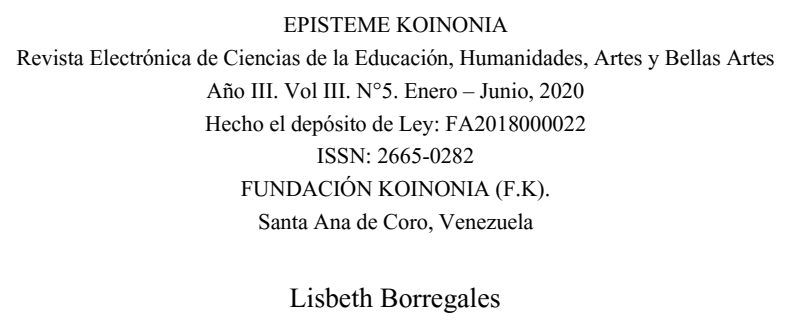

Mesopotamia y los de Caldea dominaron la escritura cuneiforme y sobre ella dejaron su conocimiento sobre la astronomía y la astrología.

Esta escritura cuneiforme la utilizaron los asirios, los persas y los medos. Su sistema de escritura consistía en que se grababa en tablillas y cilindros de arcilla. Esta escritura se hacía de izquierda a derecha, y constaba de signos en forma de cuña que representaban palabras y sílabas. La escritura cuneiforme se expandió en una extensa región y sirvió para escribir lenguas diferentes, que no tenían entre sí ningún parentesco lingüístico. (Véase en Ferreiro, 1998; p.221).

Otras investigaciones indican que: "A los sumerios se debe la escritura cuneiforme, limitada en función expresiva, puesto que utilizaban el dibujo para representar una idea, palabra o acción". Peña (2008, p.98). Estos estudios revelaron que entre los sumerios y los acadios, "la escritura estaba a cargo de los escribas y era preservada como un "misterio", como un "tesoro secreto". Los nobles no sabían leer ni escribir" (Goody, 1968, 1996; p.48).

En consecuencia el conocimiento de la escritura, en otras palabras su competencia escrita le daba una posición social al escriba. De ahí que "El escriba está exento de efectuar tareas manuales, él es el que manda" (Childe, 1941, citado por Goody, 1968, 1996; p.48). Además "El sistema cuneiforme fue utilizado durante tres milenios y medios aproximadamente" como forma de comunicación. (Michalowski, 1994; p.63 citado por Ferreiro, 1998; p.222).

En ese sentido, llama poderosamente la atención que en la religión babilónica había una deidad, Nabu, que representaba el poder de la escritura (Dios de la escritura y el aprendizaje). Esto es una evidencia de la relevancia social e histórica que la escritura tenía en esa sociedad y el mismo sería el primer atisbo de su función epistémica asociada al aprendizaje tal como la interpretamos hoy.

Cabe señalar que los sumerios también utilizaban la escritura para conservar la información. Sin embargo, otros investigadores señalan que se empleó para contabilizar el ganado o los sacos de cereales y llevar el control administrativo como se venía 


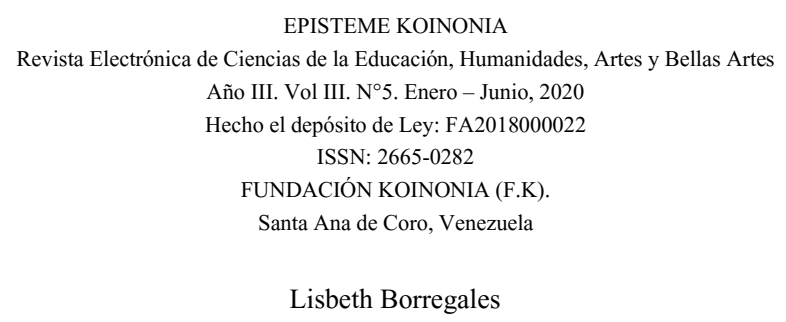

haciendo desde su invención ratificándose su uso funcional. Con el tiempo los pictogramas como sistemas de escritura evolucionaron representando ideas y sonidos. Por lo tanto, en esta civilización también la escritura se utilizó como un recurso que respondía a la necesidad comunicativa de registrar nombres personales y vocablos del extranjero empleados en el intercambio comercial. Esto generó el desarrollo de los elementos fonéticos en la escritura, por cuanto predominaba una concepción en la cual a través de la escritura se oía las voces de las páginas, la escritura captaba la voz.Por esa razón la escritura antigua emulaba el hablade las voces sagradas.

Al respecto es pertinente enfatizar que esta creencia tuvo incidencia en el modelo pedagógico de la enseñanza de la escritura en la antigüedad y todavía esa práctica subsiste en las representaciones sociales que tienen algunos docentes al vocalizar la escritura para oír la voz del escritor. A pesar del avance que en este campo se ha hecho en cuanto a las teorías de la escritura, la escuela y la formación del docente han quedado rezagadas y aisladas de esas transformaciones, por lo menos así se evidencia en Latinoamérica, donde se vienen haciendo esfuerzos en algunos países para transformar esa situación que genera un problema social y público.

En este sentido, cabe resaltar que en Babilonia se desarrolló la lexicografía, la gramática, la matemática y la jurisprudencia.Esas disciplinas incidieron en el modelo pedagógico basado en lo gramatical y en lo normativo haciendo énfasis en la correcta utilización de las letras. En resumen, es relevante mencionar que los usos que tuvo la escritura en Mesopotamia fueron identificados por Oppenhenim, (1964) entre los cuales destacan para el funcionamiento administrativo, para la aplicación de las leyes, para fines eruditos, para la formación de los escribas y la comunicación con los dioses tal como se evidencia en el:

Registro de datos para uso futuro: fines administrativos, codificación de las leyes, formulación de una tradición sagrada, para anales, eventualmente con fines eruditos, comunicación de datos en un nivel sincrónico: cartas, edictos reales, a nuncios públicos, textos para capacitar escribas. Comunicación con los dioses: textos secretos, amuletos (Citado por Goody, 1968, p.31). 
EPISTEME KOINONIA

Revista Electrónica de Ciencias de la Educación, Humanidades, Artes y Bellas Artes

Año III. Vol III. N ${ }^{\circ}$. Enero - Junio, 2020

Hecho el depósito de Ley: FA2018000022

ISSN: 2665-0282

FUNDACIÓN KOINONIA (F.K)

Santa Ana de Coro, Venezuela

Lisbeth Borregales

En relación a la civilización Fenicia antigua región del Mediterráneo Oriental. Estaban ubicados en una estrecha faja de tierra situada en la costa occidental de Siria y el Líbano. Tenía un sistema de gobierno de oligarquía, cada ciudad era independiente. Eran un pueblo de origen semítico fundaron ciudades predominantemente marítimas y comerciales. Sobresalieron por ser grandes navegantes del Mediterráneo entre los 1500 y 500 antes de Cristo. Se trataba de un pueblo culto. La lengua de los fenicios era semítica y crearon su propio alfabeto entre los años 2000 y 1500 antes de Cristo.

Entre las características que poseía el alfabeto fenicio esta tenía iniciales para sonidos inexistentes en griegos, sonidos faríngeos y obstrucción glotal, allí donde los fenicios escucharon una consonante inicial los griegos escucharon una vocal. Del alfabeto fenicio se derivó el alfabeto griego.

Al respecto Brookfield en su trabajo de investigación describió ese proceso de adquisición de la escritura en las civilizaciones agrícolas como fueron los egipcios, los mesopotámicos, los fenicios y los pueblos hebreos. Además hace énfasis en como los griegos adoptaron el alfabeto fenicio semítico. En este sentido, concluyó:

Las primeras civilizaciones que utilizaron estos caracteres fueron los antiquísimos pueblos de Mesopotamia entre ellos los sumerios y los babilonios [...] Posteriormente aparecen en Egipto los jeroglifos, los cuales nacen por la necesidad de ampliar, pero a la vez simplificar el signo [...] los fenicios efectuaron una selección de veinte caracteres fonéticos, los cuales permitían formar todas las palabras; se crea, así el alfabeto [...] los griegos adaptaron el alfabeto fenicio a su cultura [...] El alfabeto arcaico de los griegos se trasmite a los etruscos y, luego a los latinos [...] Civilizaciones como Atenas, Alejandría, y Roma fueron grandes centros de producción escrita para la confección de libros que exportaban a todo el mundo conocido en la antigüedad. Sin embargo el copiado a mano, que era el que se usaba era largo y costoso, porque solo los templos y algunas personas ricas poseían libros" (Citado por Peña, 2008, Pp.98-99).

En síntesis, de la cita se deduce cuatro aspectos fundamentales. Uno el alfabeto tuvo un origen semítico, pero fue adaptado de ahí el préstamo de las lenguas. Un segundo elemento se crea una cultura escrita restringida a una clase social dominante. Tercero las prácticas culturales que nacen con la lectura y la escritura modifican la vida del 


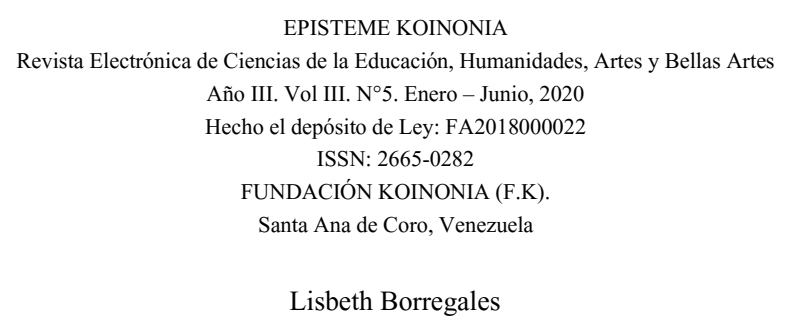

hombre de la antigüedad se crean grandes centros de producción escrita. Cuarto el modelo pedagógico se basaba en la repetición y el copiado de la letra restringiéndose el proceso de escritura a la adquisición del código escrito para descifrarlo y luego compararlo con la memoria.

\section{CONCLUSIONES}

En primer lugar la cultura escrita es un logro histórico que ha permitido crear sistemas de escrituras sobre la base del desarrollo de la humanidad. $Y$ un ejemplo de lo dicho fue que la tecnología de la palabra no sólo cumplió funciones administrativas, sino también permitió el registro que luego sería empleado para uso anales y eruditos sentando las bases para un desarrollo posterior del pensamiento crítico.

En segundo lugar la escritura antigua trataba de emular el habla, pues hubo ese proceso de transición entre la oralidad y la escritura, por tanto el contenido de la escritura era algo que se decía en voz alta, pues la restauración de la voz era crucial para la intención del significado.

En tercer lugar la escritura se caracterizó por ser analógica, metafórica, poética donde se registraban un sinfín de significados de forma inarticulada y lector debía hacer una síntesis entre líneas para hallar los significados ocultos revelándose en forma de epifaníala interpretación.

En cuarto lugar la escritura era considerada como un recurso mnemónico para recordar o registrar los hechos, las actividades económicas y las leyes, porque el conocimiento estaba en la memoria y se ejecutaba por los órganos del oído los dioses instruían ese saber al cual tenían acceso los escribas y sacerdotes, quienes mantenían una comunicación con el mundo natural y divino.

Por último, se genera un modelo de escritura gramaticalista y prescriptiva forjadora de una pedagogía basada en esa práctica para aguzar la memoria mediante la copia y el dictado. Pero lo relevante de mencionar es que aun en el siglo XXI esa práctica 


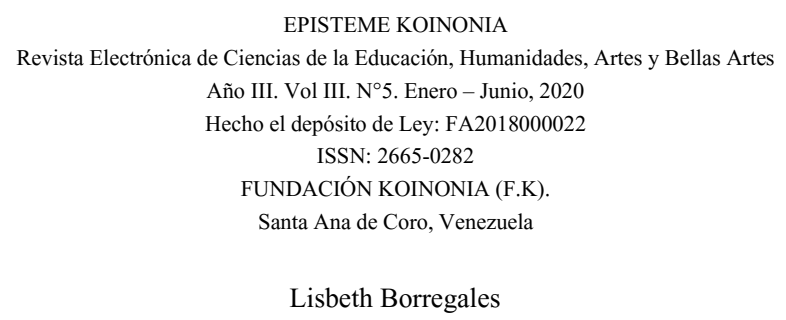

pedagógica se mantiene vigente en el aula de clase, de ahí la necesidad de transformar esa práctica tradicional.

\section{FINANCIAMIENTO}

No monetario

\section{AGRADECIMIENTOS}

Un especial agradecimiento a mi familia por el apoyo en el desarrollo de esta investigación.

\section{REFERENCIAS}

Cardona, G. (1994) Antropología de la Escritura. [Anthropology of Scripture]. Barcelona, Ediciones Gedisa.

Ferreiro, E. (1994) Diversidad y Proceso de Alfabetización. De la Celebración a la Toma de Conciencia. En: Serrón, S. (Compilador, 1998). De la Cartilla a la Construcción del Significado. [Diversity and the Literacy Process. From Celebration to Awareness. In: Serrón, S. (Compiler, 1998). From the Primer to the Construction of Meaning]. Venezuela, Editorial Tropykos.

Gran Diccionario Enciclopédico Visual (1997). [Great Visual Encyclopedic Dictionary] Colombia, Ediciones LTDA.

Goody, J. y Watt, I. (1968) Las Consecuencias de la Cultura Escrita. En Cultura Escrita en Sociedades Tradicionales, Goody, J. (Compilador, 1996). Vítale, G. y Willson, P. (Traducción). [The Consequences of Written Culture. In Written Culture in Traditional Societies, Goody, J. (Compiler, 1996). Vítale, G. and Willson, P. (Translation)]. Barcelona, Editorial Gedisa.

Kuhn, T. (2005) La Estructura de las Revoluciones Científicas. [The Structure of Scientific Revolutions]. España, Fondo de Cultura Económica.

Larousse, (2007) Gran Historia Universal, (El Alba de la Civilización), XX Vols. [Great Universal History, (The Dawn of Civilization), XX Vols.] Chile, Tomo I. 


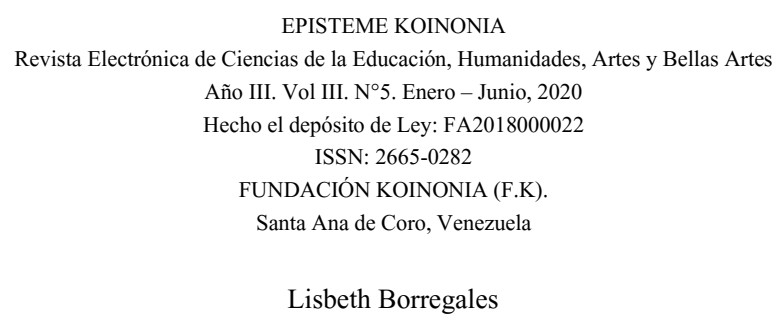

León, G. y Pinzón, V. (1997) Historia Universal (8vo Grado). [Universal History (8th Grade)]. Venezuela, Editorial McGraw Hill Interamericana de Venezuela.

McLuhan, M. (1962) La Galaxia de Gutenberg. [The Gutenberg Galaxy]. Barcelona, Editorial Planeta.

Millenium, (Geografía e Historia), III Vols. [(Geography and History), III Vols.]. España, Editorial S.L.L., 2002, III Vol.

Olson, D. (1998) El Mundo sobre Papel (El Impacto de la Escritura y la Lectura en la Estructura de Conocimiento). Willson, P. (Traductora). [The World on Paper (The Impact of Writing and Reading on the Knowledge Structure). Willson, P. (Translator).] Barcelona, Editorial Gedisa.

Olson, D. y Torrance, N. (1995) (compiladores) Cultura Escrita y Oralidad. [Written Culture and Orality]. Barcelona, Editorial Gedisa.

Ong, W. (1987,1997) Oralidad y Escritura (Tecnológica de la Palabra). Scherp, A. (Traductora). [Orality and Writing (Technological of the Word)]. México, Editorial Fondo de Cultura Económica.

Ong, W. (1994) Cultura Escrita y Oralidad. [Written Culture and Orality]. Colombia, Editorial F.C.E.

Peña, J. (2008) La Construcción Social de la Lengua Escrita. Revista Memoralia. (Una Huella en la Memoria Humanística de la UNELLEZ). [The Social Construction of the Written Language. Memoralia Magazine. (A Footprint in the Humanistic Memory of UNELLEZ)] Nº5. enero/diciembre. pp. 97-108.

Ponce, A. (1981) Educación y Lucha de Clases. [Education and Class Struggle]. México, Editores Mexicanos Unidos.

C2020 por el autor. Este artículo es de acceso abierto y distribuido según los términos y condiciones de la licencia Creative Commons Atribución-NoComercial-Compartirlgual 4.0 Internacional (CC BY-NC-SA 4.0) (https://creativecommons.org/licenses/by-nc-sa/4.0/). 